ISSN 2072-6694

www.mdpi.com/journal/cancers

Review

\title{
Endoscopic Palliation for Pancreatic Cancer
}

Mihir Bakhru ${ }^{1}$, Bezawit Tekola ${ }^{2}$ and Michel Kahaleh ${ }^{1,2, *}$

1 Division of Gastroenterology and Hepatology, University of Virginia, PO Box 800708, Charlottesville, VA 22908, USA; E-Mail: mihirbakhru@gmail.com (M.B.)

2 Division of Medicine, University of Virginia, PO Box 800708, Charlottesville, VA 22908, USA; E-Mail: bdt2q@virginia.edu (B.T.)

* Author to whom correspondence should be addressed; E-Mail: mkahaleh@ gmail.com; Tel.: +1-434-243-9259; Fax: +1-434-924-0491.

Received: 1 March 2011; in revised form: 1 April 2011 / Accepted: 1 April 2011 /

Published: 13 April 2011

\begin{abstract}
Pancreatic cancer is devastating due to its poor prognosis. Patients require a multidisciplinary approach to guide available options, mostly palliative because of advanced disease at presentation. Palliation including relief of biliary obstruction, gastric outlet obstruction, and cancer-related pain has become the focus in patients whose cancer is determined to be unresectable. Endoscopic stenting for biliary obstruction is an option for drainage to avoid the complications including jaundice, pruritus, infection, liver dysfunction and eventually failure. Enteral stents can relieve gastric obstruction and allow patients to resume oral intake. Pain is difficult to treat in cancer patients and endoscopic procedures such as pancreatic stenting and celiac plexus neurolysis can provide relief. The objective of endoscopic palliation is to primarily address symptoms as well improve quality of life.
\end{abstract}

Keywords: pancreatic adenocarcinoma; biliary obstruction; gastric outlet obstruction; endoscopy; stents; palliation

\section{Introduction}

Pancreatic adenocarcinoma is the fourth leading cause of cancer-related mortality in the U.S. and seventh most common in Europe, due to vascular invasion or metastasis at the time of diagnosis [1-3]. 
The median survival is less than six months and only a minority (10-20\%) of patients are considered candidates for resection at time of diagnosis. Accurate staging requires a multidisciplinary approach including imaging, tumor markers, and if available pathology via surgical exploration, to further classify the cancer's prognosis. Laparoscopic staging to determine resectability and thus prevent unnecessary exploratory laparotomies has had low detection rates and has fallen out of favor [4]. Even with those that are selected for surgical resection, the five year survival continues to be at 15-20\%, primarily due to recurrence [5].

Given this poor prognosis, palliation may be the only option and is targeted at the multiple complications that can occur with pancreatic cancer. Improving symptoms, reducing hospitalization, and trying to enhance overall quality of life are amongst the goals of palliation. Palliation not only includes radiation or chemotherapy to reduce tumor burden but also surgical, radiologic, or endoscopic interventions [6-8].

Biliary obstruction, gastric outlet obstruction, and pain due to tumor advancement in adjacent nerve plexus or pancreatic duct involvement are common sequelae of cancer [6]. Endoscopic techniques have gained favor recently and considered first line treatment due to their lower complication rate and associated shorter hospital stay $[9,10]$.

\section{Management of Biliary Obstruction}

Mass at the head of the pancreas is the most common location for pancreatic cancer, leading to biliary obstruction in $70-90 \%$ of patients [5,11]. Biliary obstruction can lead not only to jaundice, but pruritus, cholangitis, and hepatic dysfunction with eventual liver failure [6]. Patients survive longer if the obstructed biliary system is surgically bypassed [7]. Although surgery (preferably choledochojejunosotomy) can provide relief of obstruction and a chance of long term survival, the morbidity associated with it made endoscopic drainage more attractive [12-14]. In direct comparison to surgical drainage, endoscopic stent placement was noted to have lower procedure-related complications, improved quality of life, cost, and with similar mortality rate [9]. Several studies have analyzed cost implications of endoscopic versus surgical drainage for biliary obstruction. In one study, cost effectiveness of operative versus endoscopic management with stenting was compared for biliary obstruction from unresectable pancreatic cancer. Cost was higher from the surgical group driven by longer hospital stay and higher re-admission rate with equivalent duration of survival [15]. Artifon et al., in a prospective randomized controlled trial, compared patients with metastatic pancreatic cancer with liver metastasis $(n=30)$ who underwent either endoscopic drainage (with metal stent) or surgical drainage to evaluate to cost and quality of life. The authors found less cost $(\mathrm{p}=0.0013)$ and improved quality of life scores at 30 and 60 days $(\mathrm{p}=0.042 ; \mathrm{p}=0.05)$ with endoscopic palliation. Interestingly, no difference was seen in rates of complications, re-admissions for complications or duration of survival [16].

Several studies have studied quality of life parameters in patients deemed unresectable and with biliary obstruction, and found that biliary stenting can improve their overall well-being [17]. In addition, other symptoms such as anorexia, fatigue, and insomnia can also improve with biliary drainage [18,19]. 


\subsection{Endoscopic Technique}

Prior to endoscopy, appropriate high resolution imaging (CT or Magnetic Resonance Imaging (MRI)) is typically obtained to delineate tumor burden and a reasonable roadmap of the biliary tree. Insertion of a biliary endoprosthesis is performed via endoscopic retrograde cholangiopancreatogram (ERCP) where selective cannulation of the bile duct achieved via a catheter and over a guidewire, a stent is typically advanced through a tight stricture, and deployed across the ampulla and into the duodenum. Biliary stent allows for drainage with subsequent relief of jaundice and pruritus with success rate of insertion at 90-95\% in most experienced centers [20]. Endoscopic failures can occur and associated with limited access to major papilla from duodenal obstruction, inability to cannulate common bile duct or complex strictures. Complications include, but are not limited to, bleeding, cholangitis, pancreatitis and perforation.

\subsection{Review of the Literature}

Initially, plastic stents were used for palliation and rapidly gained popularity due to ease of use and relatively low cost. The median patency rates were approximately 3-4 months [21,22]. The main limiting factors to plastic stents not only included patency but also migration. In addition, the stent was a nidus for infection as intestinal bacterial flora had access to the biliary system, as well as obstruction due to a biofilm that eventually encases the stent lumen [23]. It was soon realized that larger diameter (then 10 French or $3.3 \mathrm{~mm}$ ) would provide better stent patency [24,25].

With the evolution of self-expandable metal stents (SEMS) patency length was improved. Using small caliber catheter delivery system (7.5-10 French) accommodating the working channel of the endoscope, the SEMS is deployed across the malignant biliary stricture up to 30 French. The larger diameter allows for enhanced patency, up to 10 months. A meta-analysis comparing plastic to metal biliary stents demonstrated no statistical difference in technical success, therapeutic success, complications, or 30 day mortality but did show a lower risk of biliary obstruction for the latter [26]. Cost effectiveness in this analysis was inconclusive, thought to be due to patient length of survival. More recently, a study from Korea compared costs of metal versus plastic stent for unresectable malignant biliary obstruction, where costs of ERCP are lower than that of metal stents. Stent occlusion was higher in the plastic stent group in a shorter amount of time (133 vs. 278 days; $p=0.0004)$ as well as a higher rate of cholangitis and associated length of hospitalization, with no statistically significant cost difference (\$1488.77 metal stent group vs. \$1319.26 plastic stent group; $\mathrm{p}=0.422$ ) [27].

Interestingly and supported by the previous studies, survival was no different and fuels the debate about what stent is most appropriate. Most endoscopists would agree that prognosis plays a large part in this decision, as metal stents provide the most benefit in patients expected to survive at least 4-6 months [28]. The rationale for this approach is that if the patient will not survive for the next 4-6 months, the patency advantage will not be of benefit as plastic stents can be patent for 3-4 months [29-31].

SEMS initially were uncovered and this feature did not make them removable in case of malfunction and allowed for tumor ingrowth and mucosal hyperplasia [32]. These factors limited the patency and lead to the evolution of first partially covered and then fully covered SEMS, with the goal of negating tumor ingrowth. A multicenter randomized control trial comparing covered and uncovered 
SEMS showed better patency and lower occlusion for covered SEMS (mean 304 days vs. 166 days for uncovered stent) [33]. However more recent studies have failed to confirm this data [34,35]. Most recently, Telford et al. compared uncovered SEMS to partially covered SEMS (Wallstent, Boston Scientific, Natick MA) in patients with inoperable distal malignant obstruction and found no difference in rate of biliary obstruction $(\mathrm{p}=0.53)$ or patient survival $(\mathrm{p}=997)$, although the partially covered stent was prone to migration ( $\mathrm{p}=0061$ ) [34]. It is still unclear which stent is ideal as limitations exist for both uncovered (described above) and for covered stents such as migration, and cholecystitis (by occluding cystic duct drainage-noted by both stent types) [36,37]. One new trend currently noticed in the literature is the increase use of metal stents in the setting of neo-adjuvant protocols (with delayed surgery) or as a first-intention intervention regardless of resectability as demonstrated by our group [36,38]. All data available so far seem to demonstrate the cost-effectiveness of such a concept [39]. Furthermore, a recent study by van der Gaag et al. argues against preoperative biliary decompression using plastic stents [40].

\section{Management of Gastric Outlet Obstruction}

Gastric outlet obstruction (GOO) is one of the later presentations of pancreatic cancer, occurring in 10-20\% of patients, which leads to a mass effect from the pancreatic head obstructing the duodenum [41,42]. Historically, surgical bypass (via gastrojejunostomy) was the only option despite its significant morbidity and mortality. Recently, endoscopic approach to treat obstruction has emerged, while laparoscopic surgery remains another option [43].

\subsection{Endoscopic Technique}

In order to place a stent for relieving an obstruction, the location and the extent of tumor involvement is defined via imaging (i.e., oral contrast study).

Endoscopic method gives better access to the duodenum with the ability to visualize to the site of obstruction. There are ongoing studies about the use of increasing types, shapes and sizes of stents with different compositions, however there are only two that are FDA approved: Enteral Wallstent (Boston Scientific, Natick, Massachusetts) and its newer version the Enteral Wallflex (Boston Scientific) for duodenal stenting that can be advanced into the working channel of a standard endoscope [44]. Once the site is reached, the selected stent should be 3-4 cm longer than the stricture, and may even require that stents be overlapped for adequate relief of obstruction [45]. Contrast and fluoroscopy is used to assure passage of obstruction as well as appropriate positioning of the stent. Common problems encountered with stenting of the duodenum include biliary obstruction in up to $40 \%$ of these patients requiring percutaneous or endoscopic drainage [46]. One proposal to avoiding this complication is to place a biliary stent before attempting enteral stenting. Failures are related to inability to cross the stricture due to complete obstruction, inaccessible distal strictures, functional gastric outlet obstruction, or peritoneal carcinomatosis or gastroparesis [45]. In these cases, the best option for palliation is to place a venting gastrostomy. As with endoscopic procedures, duodenal stenting carries risks of bowel perforation, bleeding, stent malposition and/or migration and worse case, fistula formation [45]. 


\subsection{Review of the Literature}

The success of duodenal stenting are measured by the patient returning to oral intake, with an average rate of $87-100 \%$ with minimal complication rates as low as $1.2 \%$ [47]. Philips et al. have one of the largest series of patients with enteral stenting involving 46 patients with reported $100 \%$ success rates of SEMS deployment and $91 \%$ clinical success rate [48]. Even though surgical bypass is historically a standard of treatment of GOO, recent data supports endoscopic duodenal stenting as a preferred alternative [9]. Stenting proved to be $1 / 3$ of the cost of surgery with decreased hospital admission days [40]. Another major advantage is that patients are able to eat as early as two days post-operatively day as reported by Fiori et al., which is a major goal of palliation [49].

\section{Management of Pain}

Pain is a debilitating symptom in pancreatic cancer which severely affects quality of life. Patients with advanced pancreatic cancer can present with severe pain due pancreatic duct obstruction or nerve involvement [50,51]. One way to alleviate the pain and improve quality of life is palliative pancreatic duct stenting to relieve the obstruction [50,52]. A recent review of available evidence shows complete relief of pain in $60 \%$ of patients and at least partial relief in $25 \%$ [53].

Although much of the data measures outcome in symptom control, there is paucity in data regarding the complication rates (including risks such as stent migration, occlusion, or infection) in these patients.

Since pain can be related to neural plexus involvement, celiac plexus ablation has been offered. The technique has evolved in the past century to currently include injection of neurolytic agents, such as phenol or alcohol, to treat the visceral afferent pain. Some have also suggested cryotherapy or even excision therapy [54]. The traditional posterior approach is fluoroscopy guided and usually performed by anesthesiologists. This method carried the rare risk of paralysis and paresthesia due to spinal cord injury [55].

Although not as well studied, several other approaches such as splanchnic neurolysis either via surgical or radiologic approach do exist but require further research of their success rates. Splanchnic neurolysis for instance appears to carry similar risk to celiac plexus neurolysis [56].

\subsection{Endoscopic Technique}

Celiac plexus block (CPB) was first described in 1914 by Kappis et al. and has since evolved to lead to development of celiac plexus neurolysis (CPN). Both methods are now used via endoscopic ultrasound (EUS) guidance for different purposes; where CPB is mostly used for chronic pancreatitis and CPN for pancreatic cancer pain [57]. The difference between CPB and CPN is in the injected agents and the location of injection. These procedures require that the endoscopist identify the antecrural space, noted to be anterior to the celiac plexus and inject the preferred agents in the appropriate location [58]. Once the appropriate landmarks are endoscopically identified, CPB involves injecting an anesthetic such as bupivacaine and a steroid in the area of the celiac plexus or on top of the ganglia [57]. CPN evolved with the increased recognition of the celiac ganglia via EUS. Levy et al. described the efficacy of direct injection into the ganglia [59]. This technique involves the same 
identification of structures; however, it requires directly injecting the celiac ganglia with a sclerosant, such as phenol or dehydrated alcohol with an anesthetic.

\subsection{Review of the Literature}

Multiple studies conclude that both $\mathrm{CPB}$ and CPN have a significant palliative role in chronic pancreatic abdominal pain. However, it is important to note that they do not eliminate the use of pre-procedure narcotic pain management. CPB appears to be most effective for chronic pancreatitis pain rather than pancreatic cancer pain as described by a recent meta-analysis [57]. The study concluded that there was an average of $51 \%$ reduction in abdominal pain. CPN on the other hand was more efficacious in pancreatic cancer pain, with an average of $73 \%$ reduction of pain. Levy et al. described EUS-guided CPN on patients with unresectable pancreatic carcinoma and chronic pancreatitis $(n=33)$. Ninety four percent $(16 / 17)$ of patients with cancer and $4 / 5$ with chronic pancreatitis reported pain relief. Interestingly, 34\% had initial pain exacerbation thought to be related to improved therapeutic response $(p<0.05)$ [59]. A few studies reported that the efficacy of this procedure was dependent on various factors such as timing and location of the tumor. Mercadente et al. evaluated the use of narcotics post CPN and reported a transient reduction in supplemental narcotic pain management for up to four weeks post procedure then rebounded back to their original pain level if higher doses of opioids were note used. The authors concluded that CPN should be initiated earlier in the course of the pain to prevent the rebound, while the anatomy of the pancreas is still in tact to identify appropriate structures [60].

Catalano et al. reported the importance of tumor location in the efficacy of CPN, where patients with malignancy at the body or tail of the pancreas had better pain relief than those with pancreatic head cancer [61]. EUS-guided CPN carries well studied risks as described by Gunaratnam et al., with hyperalgesia in $9 \%$, postural hypotension in $20 \%$ and diarrhea in $7 \%$ of the patients, all of which were noted to be transient symptoms [62]. The benefit includes sustained pain relief for up to 24 weeks independent of adjuvant therapy [62].

\section{Conclusions}

Pancreatic cancer has very poor prognosis and often palliative procedures are the only option for patients to relieve their symptoms and improve their quality of life. Patients benefit from endoscopic approaches to treat biliary obstruction, gastric outlet obstruction, and cancer-related pain. Indication for endoscopic intervention is determined on a number of factors including patients' prognosis and life expectancy.

\section{References}

1. Jemal, A.; Siegel, R.; Xu, J.; Ward, E. Cancer statistics, 2010. CA Cancer J. Clin. 2010, 60, 277-300.

2. DiMagno, E.P.; Reber, H.A.; Tempero, M.A. AGA technical review on the epidemiology, diagnosis, and treatment of pancreatic ductal adenocarcinoma. Gastroenterology 1999, 117, 1464-1484. 
3. Greenlee, R.T.; Hill-Harmon, M.B.; Murray, T.; Thun, M. Cancer statistics, 2001. CA Cancer J. Clin. 2001, 51, 15-36.

4. Nieveen van Dijkum, E.J.; Romijn, M.G.; Terwee, C.B.; de Wit, L.T.; van der Meulen, J.H.; Lameris, H.S.; Rauws, E.A.; Obertop, H.; van Eyck, C.H.; Bossuyt, P.M.; et al. Laparoscopic staging and subsequent palliation in patients with peripancreatic carcinoma. Ann. Surg. 2003, 237, $66-73$.

5. Hua, Y.P.; Liang, L.J.; Peng, B.G.; Li, S.Q.; Huang, J.F. Pancreatic head carcinoma: Clinical analysis of 189 cases. HNPD Int. 2009, 8, 79-84.

6. Warshaw, A.L.; Fernandez-del Castillo, C. Pancreatic carcinoma. N. Engl. J. Med. 1992, 326, 455-465.

7. van den Bosch, R.P.; van der Schelling, G.P.; Klinkenbijl, J.H.; Mulder, P.G.; van Blankenstein, M.; Jeekel, J. Guidelines for the application of surgery and endoprostheses in the palliation of obstructive jaundice in advanced cancer of the pancreas. Ann. Surg. 1994, 219, 18-24.

8. Lillemoe, K.D.; Cameron, J.L.; Kaufman, H.S.; Yeo, C.J.; Pitt, H.A.; Sauter, P.K. Chemical splanchnicectomy in patients with unresectable pancreatic cancer. A prospective randomized trial. Ann. Surg. 1993, 217, 447-455; discussion in 456-457.

9. Smith, A.C.; Dowsett, J.F.; Russell, R.C.; Hatfield, A.R.; Cotton, P.B. Randomised trial of endoscopic stenting versus surgical bypass in malignant low bileduct obstruction. Lancet 1994, 344, 1655-1660.

10. Kozarek, R.A. Endoscopy in the management of malignant obstructive jaundice. Gastrointest. Endoscop. Clin. North Am. 1996, 6, 153-176.

11. Kalser, M.H.; Barkin, J.; MacIntyre, J.M. Pancreatic cancer. Assessment of prognosis by clinical presentation. Cancer 1985, 56, 397-402.

12. Moss, A.C.; Morris, E.; Leyden, J.; MacMathuna, P. Malignant distal biliary obstruction: A systematic review and meta-analysis of endoscopic and surgical bypass results. Cancer Treat. Rev. 2007, 33, 213-221.

13. Sarfeh, I.J.; Rypins, E.B.; Jakowatz, J.G.; Juler, G.L. A prospective, randomized clinical investigation of cholecystoenterostomy and choledochoenterostomy. Am. J. Surg. 1988, 155, 411-414.

14. Gouma, D.J.; Busch, O.R.; Van Gulik, T.M. Pancreatic carcinoma: Palliative surgical and endoscopic treatment. HPB (Oxford) 2006, 8, 369-376.

15 Raikar, G.V.; Melin, M.M.; Ress, A.; Lettieri, S.Z.; Poterucha, J.J.; Nagorney, D.M.; Donohue, J.H. Cost-effective analysis of surgical palliation versus endoscopic stenting in the management of unresectable pancreatic cancer. Ann. Surg. Oncol. 1996, 3, 470-475.

16. Artifon, E.L.; Sakai, P.; Cunha, J.E.; Dupont, A.; Filho, F.M.; Hondo, F.Y.; Ishioka, S.; Raju, G.S. Surgery or endoscopy for palliation of biliary obstruction due to metastatic pancreatic cancer. Am. J. Gastroenterol. 2006, 101, 2031-2037.

17. Abraham, N.S.; Barkun, J.S.; Barkun, A.N. Palliation of malignant biliary obstruction: A prospective trial examining impact on quality of life. Gastrointest. Endosc. 2002, 56, 835-841.

18. Luman, W.; Cull, A.; Palmer, K.R. Quality of life in patients stented for malignant biliary obstructions. Eur. J. Gastroenterol. Hepatol. 1997, 9, 481-484.

19. Ballinger, A.B.; McHugh, M.; Catnach, S.M.; Alstead, E.M.; Clark, M.L. Symptom relief and quality of life after stenting for malignant bile duct obstruction. Gut 1994, 35, 467-470. 
20. Levy, M.J.; Baron, T.H.; Gostout, C.J.; Petersen, B.T.; Farnell, M.B. Palliation of malignant extrahepatic biliary obstruction with plastic versus expandable metal stents: An evidence-based approach. Clin. Gastroenterol. Hepatol. 2004, 2, 273-285.

21. Cotton, P.B. Nonsurgical palliation of jaundice in pancreatic cancer. Surg. Clin. North Am. 1989, 69, 613-627.

22. Brandabur, J.J.; Kozarek, R.A.; Ball, T.J.; Hofer, B.O.; Ryan, J.A., Jr; Traverso, L.W.; Freeny, P.C.; Lewis, G.P. Nonoperative versus operative treatment of obstructive jaundice in pancreatic cancer: Cost and survival analysis. Am. J. Gastroenterol. 1988, 83, 1132-1139.

23. Sung, J.Y.; Costerton, J.W.; Shaffer, E.A. Defense system in the biliary tract against bacterial infection. Dig. Dis. Sci. 1992, 37, 689-696.

24. Siegel, J.H.; Snady, H. The significance of endoscopically placed prostheses in the management of biliary obstruction due to carcinoma of the pancreas: Results of nonoperative decompression in 277 patients. Am. J. Gastroenterol. 1986, 81, 634-641.

25. Walta, D.C.; Fausel, C.S.; Brant, B. Endoscopic biliary stents and obstructive jaundice. Am. J. Surg. 1987, 153, 444-447.

26. Moss, A.C.; Morris, E.; Mac Mathuna, P. Palliative biliary stents for obstructing pancreatic carcinoma. Cochrane Database Syst. Rev. 2006, 2, CD004200.

27. Yoon, W.J.; Ryu, J.K.; Yang, K.Y.; Paik, W.H.; Lee, J.K.; Woo, S.M.; Park, J.K.; Kim, Y.T.; Yoon, Y.B. A comparison of metal and plastic stents for the relief of jaundice in unresectable malignant biliary obstruction in Korea: An emphasis on cost-effectiveness in a country with a low ERCP cost. Gastrointest. Endosc. 2009, 70, 284-289.

28. Yeoh, K.G.; Zimmerman, M.J.; Cunningham, J.T.; Cotton, P.B. Comparative costs of metal versus plastic biliary stent strategies for malignant obstructive jaundice by decision analysis. Gastrointest. Endosc. 1999, 49, 466-471.

29. Arguedas, M.R.; Heudebert, G.H.; Stinnett, A.A.; Wilcox, C.M. Biliary stents in malignant obstructive jaundice due to pancreatic carcinoma: a cost-effectiveness analysis. Am. J. Gastroenterol. 2002, 97, 898-904.

30. Schmassmann, A.; von Gunten, E.; Knuchel, J.; Scheurer, U.; Fehr, H.F.; Halter, F. Wallstents versus plastic stents in malignant biliary obstruction: Effects of stent patency of the first and second stent on patient compliance and survival. Am. J. Gastroenterol. 1996, 91, 654-659.

31. Prat, F.; Chapat, O.; Ducot, B.; Ponchon, T.; Pelletier, G.; Fritsch, J.; Choury, A.D.; Buffet, C. A randomized trial of endoscopic drainage methods for inoperable malignant strictures of the common bile duct. Gastrointest. Endosc. 1998, 47, 1-7.

32. Davids, P.H.; Groen, A.K.; Rauws, E.A.; Tytgat, G.N.; Huibregtse, K. Randomised Trial of self-expanding metal stents versus polyethylene stents for distal malignant biliary obstruction. Lancet 1992, 340, 1488-1492.

33. Isayama, H.; Komatsu, Y.; Tsujino, T.; Sasahira, N.; Hirano, K.; Toda, N.; Nakai, Y.; Yamamoto, N.; Tada, M.; Yoshida, H.; et al. A prospective randomised study of "covered" versus "uncovered" diamond stents for the management of distal malignant biliary obstruction. Gut 2004, $53,729-734$. 
34. Telford, J.J.; Carr-Locke, D.L.; Baron, T.H.; Poneros, J.M.; Bounds, B.C.; Kelsey, P.B.; Schapiro, R.H.; Huang, C.S.; Lichtenstein, D.R.; Jacobson, B.C.; et al. A randomized trial comparing uncovered and partially covered self-expandable metal stents in the palliation of distal malignant biliary obstruction. Gastrointest. Endosc. 2010, 72, 907-914.

35. Yoon, W.J.; Lee, J.K.; Lee, K.H.; Lee, W.J.; Ryu, J.K.; Kim, Y.T.; Yoon, Y.B. A comparison of covered and uncovered wallstents for the management of distal malignant biliary obstruction. Gastrointest. Endosc. 2006, 63, 996-1000.

36. Kahaleh, M.; Tokar, J.; Conaway, M.R.; Brock, A.; Le, T.; Adams, R.B.; Yeaton, P. Efficacy and complications of covered wallstents in malignant distal biliary obstruction. Gastrointest. Endosc. 2005, 61, 528-533.

37. Fumex, F.; Coumaros, D.; Napoleon, B.; Barthet, M.; Laugier, R.; Yzet, T.; Le Sidaner, A.; Desurmont, P.; Lamouliatte, H.; Letard, J.C.; et al. Similar performance but higher cholecystitis rate with covered biliary stents: Results from a prospective multicenter evaluation. Endoscopy 2006, 38, 787-792.

38. Wasan, S.M.; Ross, W.A.; Staerkel, G.A.; Lee, J.H. Use of expandable metallic biliary stents in resectable pancreatic cancer. Am. J. Gastroenterol. 2005, 100, 2056-2061.

39. Vauthey, J.N.; Dixon, E. AHPBA/SSO/SSAT consensus conference on resectable and borderline resectable pancreatic cancer: Rationale and overview of the conference. Ann. Surg. Oncol. 2009, $16,1725-1726$.

40. van der Gaag, N.A.; Rauws, E.A.; van Eijck, C.H.; Bruno, M.J.; van der Harst, E.; Kubben, F.J.; Gerritsen, J.J.; Greve, J.W.; Gerhards, M.F.; de Hingh, I.H.; et al. Preoperative biliary drainage for cancer of the head of the pancreas. N. Engl. J. Med. 2010, 362, 129-137.

41. Schantz, S.P.; Schickler, W.; Evans, T.K.; Coffey, R.J. Palliative gastroenterostomy for pancreatic cancer. Am. J. Surg. 1984, 147, 793-796.

42. Van Heek, N.T.; De Castro, S.M.; van Eijck, C.H.; van Geenen, R.C.; Hesselink, E.J.; Breslau, P.J.; Tran, T.C.; Kazemier, G.; Visser, M.R.; Busch, O.R.; et al. The need for a prophylactic gastrojejunostomy for unresectable periampullary cancer: A prospective randomized multicenter trial with special focus on assessment of quality of life. Ann. Surg. 2003, 238, 894-902, discussion in 902-905.

43. Choi, Y.B. Laparoscopic gatrojejunostomy for palliation of gastric outlet obstruction in unresectable gastric cancer. Surg. Endosc. 2002, 16, 1620-1626.

44. Kruse, E.J. Palliation in pancreatic cancer. Surg. Clin. North Am. 2010, 90, 355-364.

45. Sanders, M.; Papachristou, G.I.; McGrath, K.M.; Slivka, A. Endoscopic palliation of pancreatic cancer. Gastroenterol. Clin. North Am. 2007, 36, 455-476.

46. Mosler, P.; Mergener, K.D.; Brandabur, J.J.; Schembre, D.B.; Kozarek, R.A. Palliation of gastric outlet obstruction and proximal small bowel obstruction with self-expandable metal stents: A single center series. J. Clin. Gastroenterol. 2005, 39, 124-128.

47. Yim, H.B.; Jacobson, B.C.; Saltzman, J.R.; Johannes, R.S.; Bounds, B.C.; Lee, J.H.; Shields, S.J.; Ruymann, F.W.; Van Dam, J.; Carr-Locke, D.L. Clinical outcome of the use of enteral stents for palliation of patients with malignant upper GI obstruction. Gastrointest. Endosc. 2001, 53, 329-332.

48. Phillips, M.S.; Gosain, S.; Bonatti, H.; Friel, C.M.; Ellen, K.; Northup, P.G.; Kahaleh, M. Enteral stents for malignancy: A report of 46 consecutive cases over 10 years, with critical review of complications. J. Gastrointest. Surg. 2008, 12, 2045-2050. 
49. Fiori, E.; Lamazza, A.; Volpino, P.; Burza, A.; Paparelli, C.; Cavallaro, G.; Schillaci, A.; Cangemi, V. Palliative management of malignant antro-pyloric strictures. Gastroenterostomy vs. endoscopic stenting. A Randomized prospective trial. Anticancer Res. 2004, 24, 269-271.

50. Costamagna, G.; Alevras, P.; Palladino, F.; Rainoldi, F.; Mutignani, M.; Morganti, A. Endoscopic Pancreatic stenting in pancreatic cancer. Can. J. Gastroenterol. 1999, 13, 481-487.

51. Moore, J.C.; Adler, D.G. Celiac plexus neurolysis for pain relief in pancreatic cancer. J. Support. Oncol. 2009, 7, 83-87, 90.

52. Tham, T.C.; Lichtenstein, D.R.; Vandervoort, J.; Wong, R.C.; Slivka, A.; Banks, P.A.; Yim, H.B.; Carr-Locke, D.L. Pancreatic duct stents for "obstructive type" pain in pancreatic malignancy. Am. J. Gastroenterol. 2000, 95, 956-960.

53. Costamagna, G.; Mutignani, M. Pancreatic stenting for malignant ductal obstruction. Dig. Liver Dis. 2004, 36, 635-638.

54. Srikureja, W.; Chang, K.J. Endoscopic palliation of pancreatic adenocarcinoma. Curr. Opin. Gastroenterol. 2005, 21, 601-605.

55. Romanelli, D.F.; Beckmann, C.F.; Heiss, F.W. Celiac plexus block: Efficacy and safety of the anterior approach. AJR Am. J. Roentgenol. 1993, 160, 497-500.

56. Eisenberg, E.; Carr, D.B.; Chalmers, T.C. Neurolytic celiac plexus block for treatment of cancer pain: a meta-analysis. Anesth. Analg. 1995, 80, 290-295.

57. Kaufman, M.; Singh, G.; Das, S.; Concha-Parra, R.; Erber, J.; Micames, C.; Gress, F. Efficacy of endoscopic ultrasound-guided celiac plexus block and celiac plexus neurolysis for managing abdominal pain associated with chronic pancreatitis and pancreatic cancer. J. Clin. Gastroenterol. 2010, 44, 127-134.

58. Polati, E.; Finco, G.; Gottin, L.; Bassi, C.; Pederzoli, P.; Ischia, S. Prospective randomized double-blind trial of neurolytic coeliac plexus block in patients with pancreatic cancer. $B r . J$. Surg. 1998, 85, 199-201.

59. Levy, M.J.; Topazian, M.D.; Wiersema, M.J.; Clain, J.E.; Rajan, E.; Wang, K.K.; de la Mora, J.G.; Gleeson, F.C.; Pearson, R.K.; Pelaez, M.C.; et al. Initial evaluation of the efficacy and safety of endoscopic ultrasound-guided direct ganglia neurolysis and block. Am. J. Gastroenterol. 2008, 103, 98-103.

60. Mercadante, S.; Catala, E.; Arcuri, E.; Casuccio, A. Celiac plexus block for pancreatic cancer pain: Factors influencing pain, symptoms and quality of life. J. Pain Symptom Manage. 2003, 26, 1140-1147.

61. Catalano, M.; Ahmed, U.; Chauhan, S.; Patel, S.; Geenen, J. Celiac plexus neurolysis (cpn) in the treatment of refractory pain of pancreatic cancer (pca): Site specific response to therapy. Gastrointest. Endosc. 2005, 61, AB273.

62. Gunaratnam, N.T.; Sarma, A.V.; Norton, I.D.; Wiersema, M.J. A prospective study of eus-guided celiac plexus neurolysis for pancreatic cancer pain. Gastrointest. Endosc. 2001, 54, 316-324.

(C) 2011 by the authors; licensee MDPI, Basel, Switzerland. This article is an open access article distributed under the terms and conditions of the Creative Commons Attribution license (http://creativecommons.org/licenses/by/3.0/). 